\title{
The reversed eyewitness suggestibility effect
}

\author{
D. STEPHEN LINDSAY \\ Williams College, Williamstown, Massachusetts \\ and \\ MARCIA K. JOHNSON \\ Princeton University, Princeton, New Jersey
}

\begin{abstract}
The standard temporal order of events used in studies of eyewitness suggestibility was reversed: Misled subjects were given verbal suggestions about a visual scene before witnessing it. As in the standard procedure, the subjects were later tested on memory of the visual scene. A suggestibility effect was obtained with this reversed procedure, even though the verbal information could not "update" the target memory because no memory of the visual scene existed when the misleading suggestions were given.
\end{abstract}

Loftus and her colleagues (e.g., Loftus, 1979; Wells \& Loftus, 1984) have demonstrated that subjects are quite susceptible to misleading suggestions regarding recently witnessed events. The standard suggestibility procedure involves presenting visual information followed by verbal misinformation. Later, the subjects are tested on memory of the visual information. Subjects often claim to have seen things that were actually presented only in the verbal suggestions. Loftus (e.g., Loftus, 1981; Loftus \& Loftus, 1980) has argued that when subjects receive misleading suggestions, the new information is integrated into the memory representation of the visual scene through a process termed "updating." According to Loftus, new verbal information that is inconsistent with the visual scene "overwrites" and replaces relevant aspects of the previously formed memory.

Several researchers have presented evidence against the updating hypothesis and offered alternative interpretations of suggestibility. Some theorists have argued that memories of the original scene and of the misleading suggestions coexist but that the latter are more accessible (e.g., Bekerian \& Bowers, 1983; Christiaansen \& Ochalek, 1983). Others have argued that suggestibility reflects spontaneous failures to encode or retain critical details in the visual scene and demand characteristics (McCloskey \& Zaragoza, 1985).

Both accessibility and nonretention probably play roles in producing suggestibility effects, but we (Lindsay \& Johnson, in press) have argued that another factor may

This research was supported in part by National Science Foundation Grant BNS8510633 to Marcia K. Johnson. We wish to express our gratitude to Patricia Carr, Laurene Jones, and Dori Seider, who generously opened their classes to us. We also thank Ronald Kopchow for helping us make these arrangements. Thanks are also due to Collen Kelley for very helpful comments on an earlier draft of this article. Correspondence may be sent to Steve Lindsay at the Department of Psychology, Bronfman Science Center, Williams College, Williamstown, MA 01267, or to Marcia K. Johnson at the Department of Psychology, Green Hall, Princeton University, Princeton, NJ 08544. be equally, and perhaps more, important. Suggestibility effects may reflect failures of the "source-monitoring" processes by which people normally identify the sources of their memories during retrieval (Johnson, 1988; Lindsay, 1987; Lindsay \& Johnson, 1988). People sometimes have difficulty identifying the source of a memory (as when one remembers hearing a particular statement but cannot remember who made it). In addition, people sometimes mistakenly believe that a memory derived from one source has come from another (as when one believes that Liz made a statement actually uttered by Kathy). We propose that event memories are attributed to particular sources via decision-making processes performed during retrieval (source monitoring) and that suggestibility procedures create ideal conditions for source-monitoring errors. ${ }^{1}$ In support of this interpretation, we (Lindsay \& Johnson, in press) have found that suggestibility effects can be eliminated by orienting subjects to attend to the sources of their memories when they are tested (see also Zaragoza \& Koshmider, in press).

In the present experiment, we reversed the order in which visual and verbal information are normally presented in suggestibility studies: The subjects read a narrative description of a scene first, and then they viewed a slide of that scene. Later, the subjects were tested on their memory of the slide. For half of the subjects (those in the misled condition), the narrative mentioned several objects not actually present in the slide. When the misleading information was received, of course, the subjects had no memory of the visual scene to be "updated." If suggestibility is the result of a process of updating previously formed memories by adding new information, then the effect should not be obtained when the misleading suggestions precede the target event. If, on the other hand, suggestibility occurs in test when subjects misidentify a memory derived from one source as a memory derived from another, then the effect should be obtained regardless of the order in which the two sources of information were presented. ${ }^{2}$ 


\section{METHOD}

\section{Subjects}

The subjects were 71 undergraduate students of both sexes at a community college. The study was conducted as an optional demonstration experiment in three classes. The students who volunteered to participate were randomly assigned to either the misled or the control condition, such that approximately half of the students in each class were in each condition. The data from one subject in the control condition were selected at random and deleted to obtain an equal number of subjects (35) in each condition.

\section{Materials and Procedure}

The materials and procedure were identical to those used in Lindsay and Johnson (in press, Experiment 2), except that the order in which the visual and verbal information had been presented was reversed in the current study. The subjects read a 400 -word narrative description of a complex scene, performed a 2- to 3-min delay task, saw a slide of the scene for $20 \mathrm{sec}$, performed a 2- to 3-min delay task, and were then tested on their memory of the slide. Both the control and misleading narratives included a detailed description of the slide; the misleading narrative also included mention of eight objects that fit with the general theme of the scene but were not present on the slide. The test consisted of 32 items in a randomized order: 8 were present on the slide but not mentioned in either narrative (the picture-only items), 8 were present on the slide and in the narrative (the picture-and-text items), 8 were present only in the misleading narrative (the misleading-textonly items), and 8 were new distractors. The subjects were instructed to respond "yes" to items they remembered seeing on the slide and "no" to items they did not remember seeing on the slide.

\section{RESULTS}

As predicted, the subjects in the misled condition (mean $=3.5$ ) claimed that they saw significantly more of the eight suggested items than did the subjects in the control condition [mean $=2.0 ; F(1,68)=10.19, M S e=3.79$, $p<.01]$. The misled and the control subjects did not differ in responses to picture-only, picture-and-text, or new items $($ all $F \mathrm{~s}<1)$.

\section{DISCUSSION}

Relative to the controls, the subjects who had received misleading suggestions before witnessing the scene to which those suggestions referred claimed more often that they had seen suggested items in the scene. Thus, a suggestibility effect can be obtained when the misleading information precedes the event about which subjects later testify.

This finding is incompatible with the notion that suggestibility occurs when new information is integrated into and overwrites a previously formed memory. For example, the misleading narrative said that the man in the foreground of the slide was "wearing a solid burgundy tie and a tie tack." In fact, however, on the slide the man's tie was unadorned. If new information had updated older memories, then, after studying the slide, the subjects would have remembered only the plain, unadorned tie from the slide, and the memory of the suggested tie tack would have been overwritten. Instead, we found that the misled subjects quite often claimed to have seen the tie tack on the slide. Indeed, the size of the suggestibility effect obtained here (3.5 and 2.0 for the misled and control subjects, respectively) was very close to that observed in Lindsay and Johnson (in press, Experiment 2), in which the same materials were used in the standard order (3.9 and 2.3 for misled and control subjects, respectively).

Although inconsistent with the idea of updating, these results are not incompatible with the general idea that memories from different sources can become integrated. Advocates of an integration hypothesis could explain our findings by making certain assumptions. Perhaps, for example, studying the slide evokes memories derived from the text, which then alter the memory of the slide itself. If this actually happened during acquisition, of course, subjects would have the phenomenal experience of seeing suggested items in the slide as they were looking at it. It is possible that our subjects experienced such hallucinations, but we think it unlikely. A second integration account would be that memories of textual and pictorial presentations somehow spontaneously blend together in memory during the retention interval, with some incompatibilities between the two sources resolved in favor of the text and others in favor of the picture.

An alternative to describing integration as an automatic or spontaneous process of blending can be framed in terms of source monitoring. Integration may occur when people consciously reflect upon information derived from different sources without attending to or focusing on the sources of those memories. Episodes of such reflection are recorded in memory and may serve as the basis for future memory performance, in which case the rememberer may be unable to discriminate among aspects of those memories derived from different sources. That is, a mental review of information garnered from different sources may make it difficult to specify the source of particular details later on, because the most accessible memories may be memories of those reflective episodes themselves, in which information from different sources was integrated irrespective of source. Indeed, people sometimes mistake memories of reflective episodes for memories of perceptual experiences (Johnson \& Raye, 1981). Such failures in "reality monitoring" are a special case of failures in source monitoring (Johnson, 1988; Lindsay \& Johnson, 1987)

In summary, the effect obtained in the current study looks like a suggestibility effect, but it was obtained under conditions that preclude updating. The results are consistent with the idea that suggestibility may reflect a failure to identify the sources of memories during remembering. Furthermore, the idea of source monitoring can incorporate the notion that information from different sources can become integrated.

\section{REFERENCES}

Abra, J. C. (1972). List differentiation and forgetting. In C. P. Duncan, L. Sechrest, \& A. W. Melton (Eds.), Human memory: Festschrift for Benton J. Underwood (pp. 25-57). New York: Appleton-CenturyCrofts.

BEKERIAN, D. A., \& BowERs, J. M. (1983). Eyewitness testimony: Were we misled? Journal of Experimental Psychology: Learning, Memory, \& Cognition, 9, 139-145.

Christianansen, R. E., \& Ochalek, K. (1983). Editing misleading information from memory: Evidence for the coexistence of original and postevent information. Memory \& Cognition, 11, 467-475.

JoHNSON, M. K. (1988). Discriminating the origin of information. In T. F. Oltmanns \& B. A. Maher (Eds.), Delusional beliefs: Interdisciplinary perspectives (pp. 34-65). New York: Wiley.

Johnson, M. K., \& Raye, C. L. (1981). Reality monitoring. Psychological Review, 88, 67-85.

LINDSAY, D. S. (1987). Whence comes this memory? Unpublished doctoral dissertation. Princeton University, Princeton, NJ.

LiNDSAY, D. S., \& JoHNSON, M. K. (1987). Reality monitoring and eyewitness suggestibility: Young children's ability to discriminate among memories from different sources. In S. J. Ceci, M. P. Toglia, \& D. F. Ross (Eds.), Children's eyewitness memory (pp. 92-121). New York: Springer-Verlag.

LINDSAY, D. S., \& JoHNSON, M. K. (1988). Source monitoring. Unpublished manuscript.

LiNDSAY, D. S., \& JoHNSON, M. K. (in press). The eyewitness suggestibility effect and memory for source. Memory \& Cognition.

LoFrus, E. F. (1979). Eyewitness testimony. Cambridge, MA:Wiley.

LofTus, E. F. (1981). Mentalmorphosis: Alterations in memory produced by the mental bonding of new information to old. In J. Long \& A. Baddeley (Eds.), Attention and performance IX (pp. 417-434). Hillsdale, NJ: Erlbaum. 
LofTUs, E. F., \& LofTUS, G. R. (1980). On permanence of information in the human brain. American Psychologist, 35, 409-420.

McCloskey, M., \& ZaragozA, M. (1985). Misleading postevent information and memory for events: Arguments and evidence against memory impairment hypotheses. Journal of Experimental Psychology: General, 114, 1-16.

TVERSKY, B., \& TUCHIN, M. (1988). A reconciliation of the evidence on eyewitness testimony: Comments on the Loftus-McCloskey \& Zaragoza debate. Manuscript submitted for publication.

Wells, G. L., \& LofTUs, E. F. (Eds.). (1984). Eyewitness testimony: Psychological perspectives. New York: Cambridge University Press.

Zaragoza, M. S., \& Koshmider, J. W., III. (in press). Misled subjects may know more than their performance implies. Journal of $E x$ perimental Psychology: Learning, Memory, \& Cognition.

\section{NOTES}

1. Source monitoring is related to earlier work on interference and context effects in forgetting, particularly to research on list differentiation (see Abra, 1972, for review). Several recent articles have noted the similarity between suggestibility procedures and earlier work on retroactive interference (Bekerian \& Bowers, 1983; McCloskey \& Zaragoza, 1985; Tversky \& Tuchin, 1988). The source-monitoring account of eyewitness suggestibility would expect both retroactive and proactive effects.

2. A significant suggestibility effect was obtained when these materials were used in the standard order (Lindsay \& Johnson, in press).

(Manuscript received August 11, 1988.) 